\title{
Samuelson Effect and Hedging Effectiveness in the CSI 300 Index Futures
}

\author{
Chunchou Wu \\ School of Business and Management, Xiamen Huaxia University, Xiamen, China \\ Email:wucc@hxxy.edu.cn
}

How to cite this paper: $\mathrm{Wu}, \mathrm{C.C.}$ (2018) Samuelson Effect and Hedging Effectiveness in the CSI 300 Index Futures. Theoretical Economics Letters, 8, 2882-2892. https://doi.org/10.4236/tel.2018.814180

Received: June 19, 2018

Accepted: October 16, 2018

Published: October 19, 2018

Copyright $\odot 2018$ by author and Scientific Research Publishing Inc. This work is licensed under the Creative Commons Attribution International License (CC BY 4.0).

http://creativecommons.org/licenses/by/4.0/

\begin{abstract}
In this paper, we adopt the CSI 300 index futures to discuss the Samuelson effect and dissect the hedging results under both time varying volatility and futures maturities. We propose the conclusion that there is no Samuelson effect embedded in the CSI 300 Index Futures. Meanwhile, this paper infers that the optimal hedge ratios are different that is related to without and with random volatility. The maturity effect for CSI 300 index futures is also found to have a salient effect to the hedging effectiveness and the optimal hedge ratio. There is an important implication in futures hedging for this empirical study. Due to the futures hedging will relate to the time varying maturities, the maturity effect should be incorporated into consideration when hedge activity is in the process. Ignoring to deal with the effect of maturity in hedging will induce uncertain risk exposures and lead to over hedging.
\end{abstract}

\section{Keywords}

Samuelson Effect, Hedge Effectiveness, Volatility, Optimal Hedge Ratio

\section{Introduction}

Maturity effect is proposed by Samuelson [1], which conjectures that futures price volatility will increase while the futures contract nears its maturity date. Often referred to as the Samuelson effect in the related literatures, the natural intuition is based on the premise that more information on futures prices is revealed when the futures contract approaches its time to maturity. It is important to examine the relationship between time to maturity and futures price volatility for several reasons. First, investors can construct their hedging methods to minimize portfolio risk by constructing various futures contracts with different time to maturity. Second, the volatility variable will affect the derivative pricing. Moreover, the interaction between volatility and time to maturity also will affect 
the pricing on futures. Finally, the futures margin requirement is a function of futures volatility, thus the movement between time to maturity and volatility has important meaning for maintenance margin setting to futures exchange. Based on these reasons, it is no doubt that the maturity effect plays an important key role in the volatility of future prices.

Rutledge [2] proposed that increasing volatility while the maturity time approaching the time to maturity is not a consistent result and rejected the maturity effect for soybean oil and wheat futures contracts. Milonas [3] analyzed eleven commodities and found support for the maturity effect. Galloway and Kolb [4] support there are strong maturity effects in energy and agricultural commodities, but not in financial commodities and precious metals. Chen, Duan and Hung [5] study the Samuelson effect with the Nikkei 225 index futures contract. Their results are against the maturity effect. Allen and Cruickshank (2000) found strong support for the maturity effect in the majority of commodity futures in THE Singapore Derivatives Exchange, London International Financial Futures and Options Exchange and the Sydney Futures Exchange. Doung and Kalev [6] [7] utilizing the daily realized volatility to investigate the maturity effect. Doung and Kalev [6] [7] offer empirical results for maturity effect for energy, metal, agricultural and financial futures contracts. Kalev and Doung [6] [7] investigate intraday data and draw on the concept of realized range to provide empirical evidence regarding the maturity effects for 14 agricultural, metal, energy and financial futures markets in the six futures exchanges. They utilize a nonparametric test and a system of seeming unrelated regressions, the paper finds strong support for the maturity effect in agricultural futures. Gurrola and Herrerias [8] investigate the maturity effects for the case of Mexican interest rate futures. Using panel data techniques, they assess the differences in volatility patterns between contracts. Their empirical study show that the maturity effect was sometimes present, the inverse effect prevails; volatility decreases as expiration approaches. To our best knowledge, no evidence for the maturity effect is found in any of the financial futures and metal futures contracts. From these related literatures, we cannot distinguish which futures markets or target commodities will appear maturity effect clearly.

The important stock market in Mainland China is the Shanghai Stock Exchange. This exchange is launched in 1990. This market has traded two different share classes, namely A and B shares. The main differences between A and B shares are the monetary unit of account. A-shares are denominated in Chinese currency (RMB), whereas B-shares are in US dollar. On April 8, 2005, the China Securities Index Company created the CSI 300 index. The CSI 300 index ${ }^{1}$ is a value weighted stock market index comprising 300 large capitalization traded A-share stocks. The CSI 300 index covers more than $90 \%$ of the total market value in the Chinese A-share market. This CSI 300 index is the first equity index

${ }^{1}$ CSI is the abbreviation of capitalization-weighted stock index. The CSI 300 is a capitalization-weighted stock market index designed to replicate the performance of 300 stocks traded in the Shanghai and Shenzhen stock exchanges. Its value is normalized relative to a base of 1000 on December 31, 2004. 
jointly launched by the Shanghai Stock Exchange and the Shenzhen Stock Exchange, aiming to reflect the price fluctuation and performance of China's A-share market. Other trading information for Chinese financial markets can refer Sohn and Zhang [9], Han and Liang [10] and Zhang etc. [11]. Investors generally believe that the CSI 300 index reflects the major performance of the whole A-share markets in China. For the necessity of hedging, China launched its CSI 300 index futures on April 16, 2010. The CSI 300 index futures are the ones traded in the China Financial Futures Exchange. The underlying asset of the CSI 300 index futures contract is CSI 300 index. This futures contract has become one of the most actively traded financial products of the Chinese financial markets.

In this paper, we adopt the CSI 300 index futures to examine the maturity effect and the hedging effectiveness. According to our empirical results, this paper is against the Samuelson effect. Meanwhile, the dynamical volatility behavior will make the hedge effects difference. The time to maturity of the CSI 300 index futures is found to have a significant effect in statistical viewpoints on the hedging effectiveness and hedge ratio. The rest of this paper is organized as follows. Section 2 describes how our empirical models are constructed. Section 3 discusses the effectiveness and optimal hedge ratio and their financial intuitions. Section 4 demonstrates the empirical results. Section 5 concludes.

\section{Bivariate Volatility Model}

To analyze the maturity effect for futures price of the CSI 300 index futures, it is natural to introduce the conventional GARCH model with an exogenous maturity variable for fitting the futures price process. It is convincing that the GARCH models are able to capture the properties of leptokurtosis and heteroscedasticity for asset returns. Thus, similar to the Chen, Duan and Hung [5], this paper constructs the dynamical structure of the CSI index and its futures-spot basis joint models with GARCH-type forms.

Let $S_{t}$ be the spot index at date $t$, and $h_{t}$ be the conditional variance, given information set at date $t$, of the logarithmic return over the period $[t-1, t]$. The dynamics of spot index are assumed to follow the below process

$$
\begin{aligned}
& \ln \left(\frac{S_{t}}{S_{t-1}}\right)=\alpha_{0}+\lambda \sqrt{h_{t}}+\sqrt{h_{t}} \varepsilon_{t} \\
& h_{t}=\beta_{0}+\beta_{1} h_{t-1}+\beta_{2} h_{t-1}\left(\varepsilon_{t-1}-c\right)^{2}
\end{aligned}
$$

where $\varepsilon_{t}$, conditional on information set at time $t$, is a standard normal random variable. ${ }^{2}$ The $\lambda$ measures the spot index return's risk premium per unit of volatility.

The specified framework constructed in Equation (1) and (2) are the popular nonlinear asymmetric NGARCH model that has been proposed by Engle and $\mathrm{Ng}$ [12]. The nonnegative parameter $c$ captures the negative correlation between ${ }^{2}$ The normal distribution can be replaced by other distributions which only satisfied its mean is zero and variance is 1 . 
spot index return and volatility innovations that is often founded in equity markets. This asymmetry parameter $\mathrm{c}$ is useful in stating the leverage effect in equity returns, too. A positive $c$ implies a negative correlation between volatility disturbance and returns which was first proposed by Black [13]. The financial literature calls this phenomenon is leverage effect. The model can be reduced to the conventional GARCH model of Bollerslev [14] while the leverage parameter $c$ is ignored. To confirm that the conditional volatility maintains positive, the parameters $\beta_{0}, \beta_{1}$ and $\beta_{2}$ should be nonnegative. Meanwhile, $\beta_{1}+\beta_{2}\left(1+c^{2}\right)$ have to less than one.

Define the basis at date $t$ as $b_{t}\left(m_{t}\right)=S_{t}-F_{t}\left(m_{t}\right)$. If the asset to be hedged and the asset underlying the futures are the same, the basis should be zero at time to maturity of the futures contract. ${ }^{3}$ Prior to expiration, the basis may be negative or positive. Because the spot-futures basis is expected to near zero as time to maturity of specific futures contract goes to zero. Thus, it is reasonable to make the variable of the basis volatility a power function of maturity.

We continue to model the process of basis by Equation (3) and (4).

$$
\begin{gathered}
\frac{\Delta b_{t}\left(m_{t}\right)}{S_{t-1}}=\omega_{0} m_{t}^{\gamma_{1}}+\omega_{1} \frac{b_{t-1}\left(m_{t-1}\right)}{S_{t-1}}+m_{t}^{\gamma_{2}} \sqrt{q_{t}} \epsilon_{t} \\
q_{t}=a_{0}+a_{1} q_{t-1}+a_{2} q_{t-1}\left(\epsilon_{t-1}-\pi\right)^{2}
\end{gathered}
$$

To confirm that the conditional volatility of basis variable maintains positive, the parameters $a_{0}, a_{1}$ and $a_{2}$ should greater than zero. Meanwhile, again $a_{1}+a_{2}\left(1+\pi^{2}\right)$ have to less than one. The process of basis is normalized by the spot index level. It is more easily to infer the hedge ratio without losing generalization. The conditional correlation of these two innovation terms is assumed to be constant. Namely, $\operatorname{Corr}_{t-1}\left(\varepsilon_{t}, \epsilon_{t}\right)=\rho$.

The process of normalized basis is constructed to follow the NGARCH process in Equation (3) and (4), too. For the analysis about maturity effect of futures volatility, we incorporate the time to maturity variable into this NGARCH system. However, the asymmetry parameter $\pi$ for the volatility process of basis variable does not have the interpretation as a leverage effect. This parameter $\pi$ is just to capture any possible asymmetric volatility that response to the disturbance in the basis process.

For the exploration of Samuelson effect, we have to derive the dynamical relationship between time to maturity and the conditional volatility of futures from the bivariate NGARCH framework. The variance of change in futures prices can be shown as:

$$
\begin{aligned}
& \operatorname{Var}_{t-1}\left(\Delta F_{t}\left(m_{t}\right)\right)=\operatorname{Var}_{t-1}\left(\Delta S_{t}-\Delta b_{t}\left(m_{t}\right)\right) \\
& =S_{t-1}^{2}\left[\operatorname{Var}_{t-1}\left(\frac{\Delta S_{t}}{S_{t-1}}\right)-2 \operatorname{Cov}_{t-1}\left(\frac{\Delta S_{t}}{S_{t-1}}, \frac{\Delta b_{t}\left(m_{t}\right)}{S_{t-1}}\right)+\operatorname{Var}_{t-1}\left(\frac{\Delta b_{t}\left(m_{t}\right)}{S_{t-1}}\right)\right] \\
& =S_{t-1}^{2}\left(h_{t}+q_{t} m_{t}^{2 \gamma_{2}}-2 \rho \sqrt{h_{t} q_{t}} m_{t}^{\gamma_{2}}\right)
\end{aligned}
$$

${ }^{3}$ This is the usual definition for basis. However, Chen, Duan and Hung [5] adopt the different definition of basis. Namely, Basis $=$ futures price - spot price. 
We could observe the maturity effect for futures by differentiate the Equation (5) with respect to the $m_{t}$ variable.

$$
\frac{\partial \operatorname{Var}_{t-1}\left(\Delta F_{t}\left(m_{t}\right)\right)}{\partial m_{t}}=2 S_{t-1}^{2} \gamma_{2} \sqrt{h_{t} q_{t}} m_{t}^{\gamma_{2}-1}\left(m_{t}^{\gamma_{2}} \sqrt{\frac{q_{t}}{h_{t}}}-\rho\right)
$$

If the value of Equation (6) is positive, then the Samuelson effect is not supported. Contrarily, if the value of Equation (6) is negative, this phenomenon represents that the futures volatility is increasing when the time is approaching the maturity date. Namely, the Samuelson effect is satisfied. Thus, the sign of Equation (6) mainly depends on $\left(m_{t}^{\gamma_{2}} \sqrt{\frac{q_{t}}{h_{t}}}-\rho\right)$.

\section{Optimal Hedge Ratio and Hedging Effectiveness}

This paper also analyses the hedge effectiveness and optimal hedge ratio with or without the time to maturity variable. The hedge ratio is the ratio of the size of the position taken in the futures to the size of the exposure. A rational investor will choose a value for the hedge ratio that minimizes the variance of the value of the portfolio's position. Here we concentrate on the topic of minimizing portfolio risk. By definition, the optimal hedge ratio is the relative position in index futures that obtains the lowest hedged portfolio variance. The hedge effectiveness can be defined as the proportion of the variance that is eliminated by hedging operation. The concept of the futures-spot basis is useful to calculate these indicators. The optimal hedge ratio can be written as the product of the coefficient of correlation between $\Delta F_{t}$ and $\Delta S_{t}$ and the ratio of the standard deviation of $\Delta S_{t}$ to the standard deviation of $\Delta F_{t}$. We are able to denote this optimal hedge ratio by the symbol of $H_{t}$.

$$
H_{t}=\rho \frac{\sigma_{\Delta S_{t}}}{\sigma_{\Delta F_{t}\left(m_{t}\right)}}=\frac{\operatorname{Cov}_{t-1}\left(\Delta F_{t}\left(m_{t}\right), \Delta S_{t}\right)}{\operatorname{Var}_{t-1}\left(\Delta F_{t}\left(m_{t}\right)\right)}
$$

Incorporating the information of Equation (1)-(4), the optimal hedge ratio can be modified as follows.

$$
\begin{aligned}
H_{t} & =\frac{\operatorname{Cov}_{t-1}\left(\Delta S_{t}-\Delta b_{t}\left(m_{t}\right), \Delta S_{t}\right)}{\operatorname{Var}_{t-1}\left(\Delta S_{t}-\Delta b_{t}\left(m_{t}\right)\right)}=\frac{\operatorname{Cov}_{t-1}\left(\frac{\Delta S_{t}}{S_{t-1}}-\frac{\Delta b_{t}\left(m_{t}\right)}{S_{t-1}}, \frac{\Delta S_{t}}{S_{t-1}}\right)}{\operatorname{Var}_{t-1}\left(\frac{\Delta S_{t}}{S_{t-1}}-\frac{\Delta b_{t}\left(m_{t}\right)}{S_{t-1}}\right)} \\
= & \frac{\operatorname{Var}_{t-1}\left(\frac{\Delta S_{t}}{S_{t-1}}\right)-\operatorname{Cov}_{t-1}\left(\frac{\Delta b_{t}\left(m_{t}\right)}{S_{t-1}}, \frac{\Delta S_{t}}{S_{t-1}}\right)}{\operatorname{Var}_{t-1}\left(\frac{\Delta S_{t}}{S_{t-1}}\right)-2 \operatorname{Cov}_{t-1}\left(\frac{\Delta b_{t}\left(m_{t}\right)}{S_{t-1}}, \frac{\Delta S_{t}}{S_{t-1}}\right)+\operatorname{Var}_{t-1}\left(\frac{\Delta b_{t}\left(m_{t}\right)}{S_{t-1}}\right)} \\
= & \frac{h_{t}-\rho \sqrt{h_{t} q_{t}} m_{t}^{\gamma_{2}}}{h_{t}+q_{t} m_{t}^{2 \gamma_{2}}-2 \rho \sqrt{h_{t} q_{t}} m_{t}^{\gamma_{2}}}
\end{aligned}
$$

The indicator of hedging effectiveness can be defined as the variance that is 
eliminated by hedging. Based on our bivariate system, one can obtain the value of hedging effectiveness from Equation (8).

$$
\text { Effect }_{t-1}=\frac{\operatorname{Cov}_{t-1}\left[\Delta S_{t}, \Delta F_{t}\left(m_{t}\right)\right]^{2}}{\operatorname{Var}_{t-1}\left[\Delta S_{t}\right] \operatorname{Var}_{t-1}\left[\Delta F_{t}\left(m_{t}\right)\right]}=\frac{\left(h_{t}-\rho \sqrt{h_{t} q_{t}} m_{t}^{\gamma_{2}}\right)^{2}}{h_{t}\left(h_{t}+q_{t} m_{t}^{2 \gamma_{2}}-2 \rho \sqrt{h_{t} q_{t}} m_{t}^{\gamma_{2}}\right)}
$$

It is salient that the hedging effectiveness is a function of two conditional volatilities and maturity parameter from the bivariate NGARCH systems.

\section{Empirical Results}

We collect the daily data of CSI-300 futures and index spot series from 24 May 2010 to 16 December $2016 .{ }^{4}$ All the data in this study are collected from Bloomberg. This paper specially examines the nearby three-month futures contract which is switched over the next maturing contract five days before the maturity day of the nearby futures contract. Using maximum likelihood estimation based on the assumption of conditional normality for the time being. ${ }^{5}$ The results for data fitting are demonstrated in Table 1. We express the NGARCH parameter estimates with maturity effect and without maturity effect simultaneously. Namely, the $\gamma_{1}$ and $\gamma_{2}$ are set to be zero without maturity effect. From Table 1, both the basis and spot index return series have GARCH effects. Besides, all the coefficients appear to support the model conventional stable conditions. Regardless of the fact that the maturity effect is incorporated into consideration, the coefficient value for $\hat{\beta}_{1}$ is greater than that for $\hat{\beta}_{2}$. Meanwhile, $\hat{\beta}_{1}+\hat{\beta}_{2}(1+\hat{c})^{2}<1$ represents that the spot index return series is stationary and will not occur the phenomenon of divergence. $\hat{c}$ is greater than zero and significantly. This result also supports that the leverage effect is evident for CSI-300 stock index return.

Bivariate NGARCH model estimation with and without maturity effect for CSI-300 index and its basis series

$$
\begin{gathered}
\ln \left(\frac{S_{t}}{S_{t-1}}\right)=\alpha_{0}+\lambda \sqrt{h_{t}}+\sqrt{h_{t}} \varepsilon_{t} \\
h_{t}=\beta_{0}+\beta_{1} h_{t-1}+\beta_{2} h_{t-1}\left(\varepsilon_{t-1}-c\right)^{2} \\
\frac{\Delta b_{t}\left(m_{t}\right)}{S_{t-1}}=\omega_{0} m_{t}^{\gamma_{1}}+\omega_{1} \frac{b_{t-1}\left(m_{t-1}\right)}{S_{t-1}}+m_{t}^{\gamma_{2}} \sqrt{q_{t}} \epsilon_{t} \\
q_{t}=a_{0}+a_{1} q_{t-1}+a_{2} q_{t-1}\left(\epsilon_{t-1}-\pi\right)^{2}
\end{gathered}
$$

In Table 1, we found that the maturity parameters prove that the maturity effect is significant. The estimates for $\hat{\gamma}_{1}$ and $\hat{\gamma}_{2}$ suggest that the maturity effect

${ }^{4}$ The day of 24 May 2010 is the first trading day after last futures delivery day. The delivery day for current futures is the third Friday of the month. The day of 16 December 2016 is the delivery day for the current futures contract. There are 1597 daily data for empirical task.

${ }^{5}$ Even if the assumption of conditional normal is violated, the parameter estimates still have the property of consistent. The disadvantage is the loss of statistical efficiency under the approach of MLE. 
Table 1. The results for parameters estimation with and without maturity effect.

\begin{tabular}{|c|c|c|c|c|}
\hline \multicolumn{5}{|c|}{ CSI-300 spot index } \\
\hline \multicolumn{3}{|c|}{ without maturity effect } & \multicolumn{2}{|c|}{ with maturity effect } \\
\hline & estimate & St.D & estimate & St.D \\
\hline$\hat{\alpha}_{0}$ & 0.0332 & 0.012 & 0.3311 & 0.011 \\
\hline$\hat{\lambda}$ & -0.0795 & 0.042 & -0.0796 & 0.041 \\
\hline$\hat{\beta}_{0}$ & 0.0221 & 0.003 & 0.0211 & 0.002 \\
\hline$\hat{\beta}_{1}$ & 0.8611 & 0.058 & 0.8634 & 0.056 \\
\hline$\hat{\beta}_{2}$ & 0.0321 & 0.011 & 0.0319 & 0.008 \\
\hline$\hat{c}$ & 0.8592 & 0.133 & 0.8591 & 0.135 \\
\hline \multicolumn{5}{|c|}{ Basis dynamic process } \\
\hline$\hat{\omega}_{0}$ & 0.0743 & 0.012 & 0.0054 & 0.005 \\
\hline$\hat{\omega}_{1}$ & -0.2187 & 0.016 & -0.3155 & 0.017 \\
\hline$\hat{\gamma}_{1}$ & . & . & 0.7859 & 0.213 \\
\hline$\hat{\gamma}_{2}$ & . & . & 0.0538 & 0.012 \\
\hline$\hat{a}_{0}$ & 0.0074 & 0.003 & 0.0048 & 0.004 \\
\hline$\hat{a}_{1}$ & 0.8511 & 0.128 & 0.8436 & 0.197 \\
\hline$\hat{a}_{2}$ & 0.1023 & 0.074 & 0.1035 & 0.063 \\
\hline$\hat{\pi}$ & -0.0167 & 0.059 & 0.1354 & 0.067 \\
\hline$\hat{\rho}$ & -0.2135 & 0.0157 & -0.2136 & 0.0186 \\
\hline
\end{tabular}

Notes: Sample period is from 24 May 2010 to 16 December 2016. All the daily data number are 1597.

is significant by conventional significant level. ${ }^{6}$ It is apparently that the maturity factor will affect the pattern of the basis series indeed. The sign of asymmetry parameter estimate $(\hat{\pi})$ is opposite for basis dynamic process with or without the maturity effect. The coefficient for $\hat{\pi}$ suggests that disturbance in the basis series and its volatility process are negatively correlated. The magnitude of $\hat{\pi}$ is meaningful rather than its sign. ${ }^{7}$ The correlation coefficient estimate between spot index and basis process is about -0.21 . There is not significant influence with or without the maturity effect in this bivariate structure. Following the Equation (6), the maturity variable and the degree of correlation will be the pivotal factors in measuring whether there is the maturity effect which proposed by Samuelson [1].

From Section 2 in this paper, whether the Samuelson effect is supported or not is totally judged by the sign of $\left(m_{t}^{\gamma_{2}} \sqrt{\frac{q_{t}}{h_{t}}}-\rho\right)$. The estimate for $\gamma_{2}$ is

${ }^{6}$ The likelihood ratio test supports the maturity effect is significant, too. Using two times the difference of the two (restricted and unrestricted) log-likelihood function values, we can obtain the LR estimate.

${ }^{7}$ Because changing the definition of basis from the spot index price subtract its futures price to the other way round immediately flips the sign of $\pi$. 
0.0538 , the coefficient for correlation $\rho$ is -0.2136 . In Equation (6), the $m_{t}$, $q_{t}$ and $h_{t}$ are time-varying variables. In Figure 1 , all of the $\left(m_{t}^{\gamma_{2}} \sqrt{\frac{q_{t}}{h_{t}}}-\rho\right)$ values are greater than zero based on our empirical founding. We calculate the mean of $\left(m_{t}^{\gamma / 2} \sqrt{\frac{q_{t}}{h_{t}}}-\rho\right)$ and its standard deviation. They are 0.521 and 0.293 respectively. Thus, it is reasonable to reject the hypothesis of Samuelson effect in the CSI 300 index futures.

One of the advantages for futures contract is in the financial risk management. Above all, the stock index futures can be used to alter the systematic risk of a portfolio without to trade individual share. It is worth to concern the hedging relationship based on CSI 300 spot index and its futures contract. According to the Equation (7) and (8) in Section 3. We can realize the fact that the hedge ratio is a function of time to maturity and time-varying volatility. Fitting all the estimates and the series of $\hat{q}_{t}$ and $\hat{h}_{t}$ into Equation (8), we can obtain the dynamical optimal hedge ratio series and plot the pattern in Figure 2.

It is interesting to compare the dynamic optimal hedge ratio with the static hedge. The optimal hedge ratio under static hedge is the slope of the best-fit line when $\Delta S_{t}$ is regressed against $\Delta F_{t}$. This statement is very reasonable, because we require this hedge value to correspond to the ratio of changes in $\Delta S_{t}$ to changes in $\Delta F_{t}$. Using the CSI 300 index and futures data set, this static hedge ratio equals 0.961604 . In Figure 2, the horizontal line corresponds to the static

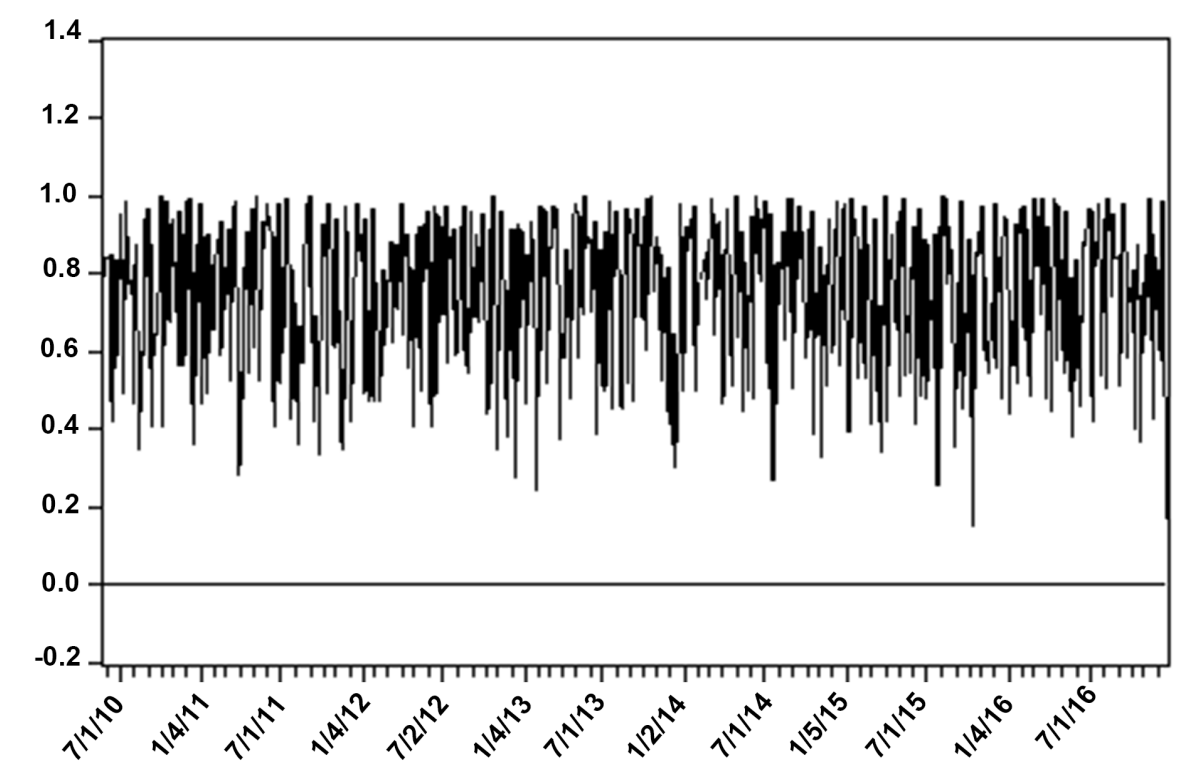

Figure 1. The $\left(m_{t}^{\gamma_{2}} \sqrt{\frac{q_{t}}{h_{t}}}-\rho\right)$ values for all the sample period. Notes: Sample period is from 24 May 2010 to 16 December 2016. This graph illustrates the derivative of the futures price volatility with respect to maturity based on Equation (6). A positive value denotes the Samuelson effect is unavailable in the CSI 300 futures market. 


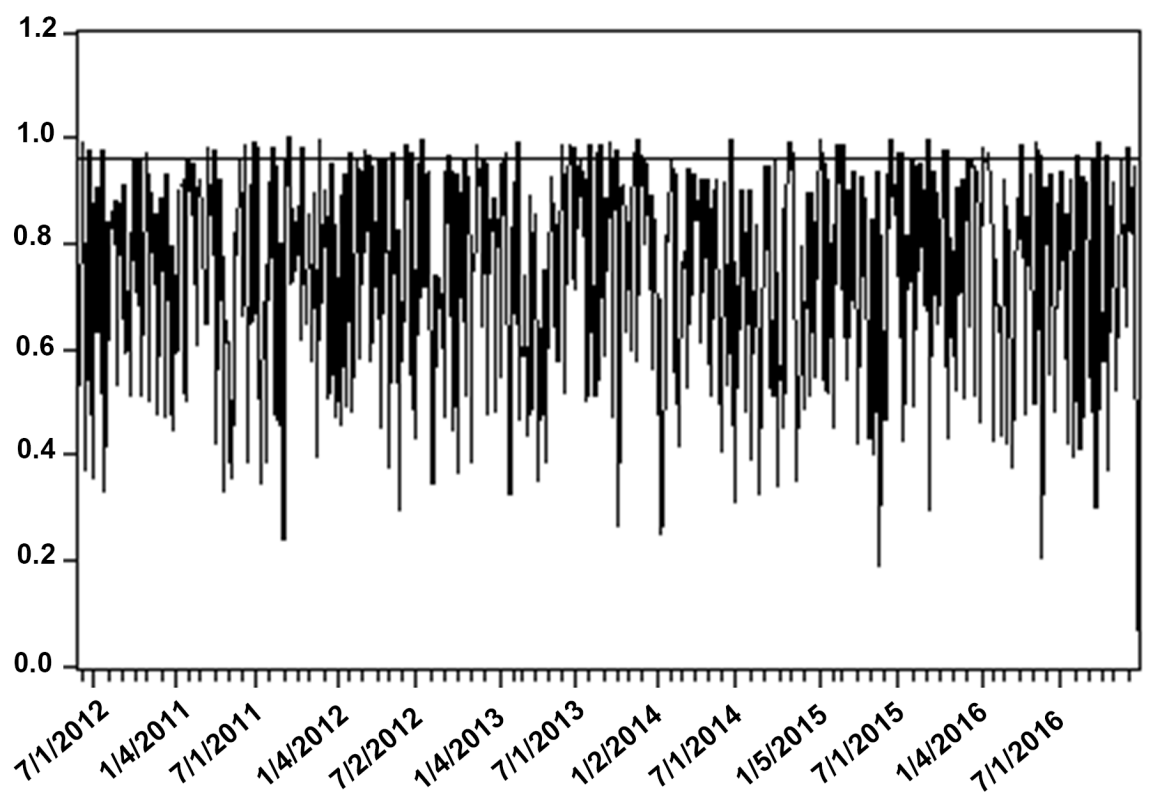

Figure 2. The pattern of dynamic optimal hedge ratio for all sample period. Notes: The horizontal line denotes the optimal hedge ratio by static hedging without maturity effect and time-varying volatility. Here the static optimal hedge ratio is 0.961604 . The curve represents the trace of optimal hedge ratio under the maturity effect and time-varying volatility is taken into consideration over the sample period. Mostly, static hedge leads to over-hedging easily.

hedge scenario. Namely, ignoring the maturity effect and constant volatility are taken into consideration. The alternative curve represents the dynamic optimal hedge ratio trace in Figure 2. We found that the curve under the horizontal line mostly in Figure 2. Apparently, ignoring maturity effect with constant volatility to perform the CSI 300 futures hedge strategy will lead to the result of over-hedging.

The hedge effectiveness can be introduced as the proportion of the variance that is reduced by hedging strategy. Based on the condition of static hedging, this is the coefficient of determination from the regression of $\Delta S_{t}$ against $\Delta F_{t}$ or equal to the square of correlation coefficient between $\Delta S_{t}$ and $\Delta F_{t}$. We obtain the value of static hedge effectiveness is 0.899585 . Using the expression of Equation (9), this indicator is measured by two time-varying volatilities and time to maturity. As contrast with the effectiveness of bivariate system, the performance of dynamical hedging is better than the conventional static hedging. The mean of effectiveness measurements is 0.924312 and its standard value is 0.00062 . Most of the effectiveness measurements are greater than 0.899585 that is static hedge effectiveness. Evidently, it is contributory to adopt an appropriate bivariate volatility structure and take the maturity effect into econometric model that can improve the entire hedging performance in the CSI 300 index.

\section{Conclusion}

This study utilizes bivariate volatility model to construct the futures and basis 
processes for CSI 300 index. These two time series can be fitted well with NGARCH system. There are many advantages for choosing basis series to replace the futures series in analyzing the Samuelson effects. Above all, we can infer the optimal hedge ratio and hedge effectiveness easily. We conclude that there is no statistical evidence to support the Samuelson effect for the process of the CSI 300 index futures. Besides, the variable of time to maturity for the CSI 300 index futures constitutes an influence on the hedge effectiveness and the optimal hedge ratio. In general, ignoring the time-varying volatility and the effect of maturity will make the result of over-hedging. Finally, the hedge effectiveness is significantly better with the consideration of maturity effect than without the maturity effect. This paper contributes to the financial practices in the following ways. First, as the margin requirement is positively related to the futures price volatility, the relationship between time to maturity and volatility process has essential implication for margin pricing in CSI 300 index futures markets. Second, hedgers are able to perform hedging strategies to minimize portfolio's volatility by replacing among various futures contracts with different time to maturity. Finally, the time varying volatility is a pivot input for option pricing, the interaction between volatility and time to maturity also has implications for pricing options on futures.

\section{Conflicts of Interest}

The author declares no conflicts of interest regarding the publication of this paper.

\section{References}

[1] Samuelson, P. (1965) Proof That Properly Anticipated Prices Fluctuate Randomly. Industrial Management Review, 6, 41-49.

[2] Rutledge, D.J.S. (1976) A Note on the Variability of Futures Prices. Review of Economics and Statistics, 58, 118-120. https://doi.org/10.2307/1936017

[3] Milonas, N. (1986) Price Variability and the Maturity Effect in the Futures Markets. Journal of Futures Markets, 6, 443-460. https://doi.org/10.1002/fut.3990060309

[4] Galloway, T.M. and Kolb, R.W. (1996) Futures Prices and the Maturity Effect. Journal of Futures Markets, 16, 809-828. https://doi.org/10.1002/(SICI)1096-9934(199610)16:7<809::AID-FUT5>3.0.CO;2-S

[5] Chen, Y.J., Duan, J.C. and Hung, M.W. (1999) Volatility and Maturity Effects in the Nikkei Index Futures. Journal of Futures Markets, 19, 895-909. https://doi.org/10.1002/(SICI)1096-9934(199912)19:8<895::AID-FUT3>3.0.CO;2-C

[6] Duong, H.N. and Kalev, P.S. (2008) The Samuelson Hypothesis in the Futures Market: An Analysis Using Intraday Data. Journal of Banking and Finance, 32, 489-500. https://doi.org/10.1016/j.jbankfin.2007.06.011

[7] Kalev, P.S. and Duong, H.N. (2008) A Test of the Samuelson Hypothesis Using Realized Range. Journal of Futures Markets, 28, 680-696.

https://doi.org/10.1002/fut.20328

[8] Gurrola, P. and Herrerias, R. (2011) Maturity Effects in the Mexican Interest Rate Futures Market. Journal of Futures Markets, 31, 371-393. 
https://doi.org/10.1002/fut.20477

[9] Sohn, S. and Zhang, X.F. (2017) Could the Extended Trading of CSI 300 Index Futures Facilitate Its Role of Price Discovery? Journal of Futures Markets, 37, 717-740. https://doi.org/10.1002/fut.21804

[10] Han, Q. and Liang, J. (2017) Index Futures Trading Restrictions and Spot Market Quality: Evidence from the Recent Chinese Stock Market Crash. Journal of Futures Markets, 37, 411-428. https://doi.org/10.1002/fut.21825

[11] Zhang, W., Huang, K., Feng, X. and Zhang, Y. (2017) Market Marker Competition and Price Efficiency: Evidence from China. Economic Modelling, 66, 121-131. https://doi.org/10.1016/j.econmod.2017.06.004

[12] Engle, R. and Ng, V. (1993) Measuring and Testing the Impact of News on Volatility. Journal of Finance, 48, 1749-1778. https://doi.org/10.1111/j.1540-6261.1993.tb05127.x

[13] Black, F. (1976) Studies in Stock Price Volatility Changes. Proceeding of the 1976 Meeting of the Business and Econsomics Statistics Section, American Statistical Association, 177-181.

[14] Bollerslev, T. (1986) General Autoregressive Conditional Heteroscedasticity. Journal of Econometrics, 31, 307-327. https://doi.org/10.1016/0304-4076(86)90063-1 